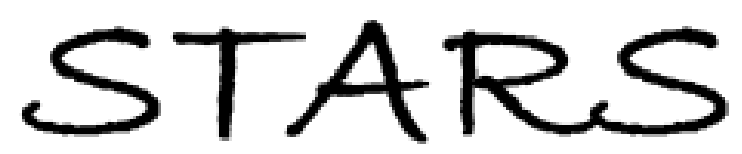

University of Central Florida

STARS

Faculty Scholarship and Creative Works

8-8-2015

\title{
Consumer Reviews and the Creation of Booking Transaction Value: Lessons from the Hotel Industry
}

\author{
Edwin N. Torres \\ University of Central Florida, edwin.torres@ucf.edu \\ Dipendra Singh \\ University of Central Florida, dipendra.singh@ucf.edu \\ April Robertson-Ring
}

Part of the Hospitality Administration and Management Commons, and the Tourism and Travel Commons

Find similar works at: https://stars.library.ucf.edu/ucfscholar

University of Central Florida Libraries http://library.ucf.edu

This Paper is brought to you for free and open access by STARS. It has been accepted for inclusion in Faculty Scholarship and Creative Works by an authorized administrator of STARS. For more information, please contact STARS@ucf.edu.

\section{Original Citation}

Torres, E. N., Singh, D., \& Robertson-Ring, A. (2015). Consumer reviews and the creation of booking transaction value: Lessons from the hotel industry. International Journal of Hospitality Management, 20, 77-83.

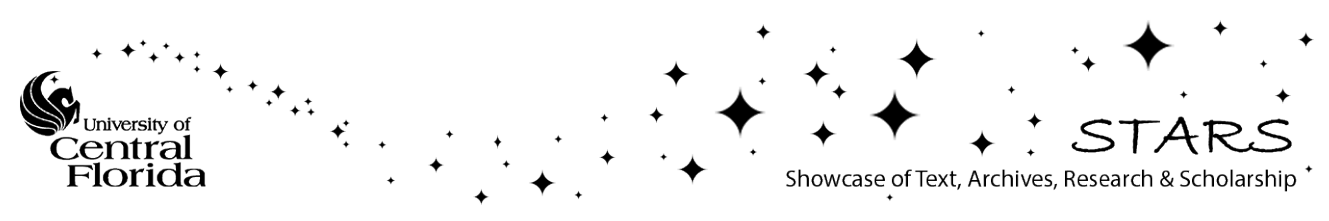




\title{
Consumer reviews and the creation of booking transaction value:
}

\section{Lessons from the hotel industry}

\begin{abstract}
In recent years, much has been said about online consumer-generated feedback. Concern typically emerges regarding consumer decision-making as well as the preservation of an organization's image. Additionally, a company's financial performance can be affected by customer online ratings. The present study explores the impact of a hotel's rating and number of reviews on the value generated through online transactions. Through collaboration with consulting company Travel Click, the research team gathered a sample of 178 hotels representing various companies and brands within the United States. Research results demonstrate that Trip Advisor ratings as well as the number of reviews had positive relationship with the average size of each online booking transaction. The paper concludes with theoretical and practical implications.
\end{abstract}

Key words: Consumer-generated feedback, Online Reviews, Hotel Finance, Lodging 


\section{Introduction}

Many of today's managers are concerned about their online image. Scholars have been equally concerned about the emergence of consumer-generated feedback and have studied topics such consumer decision making (Sparks \& Browning, 2011; Williams et.al., 2010;

Vermeulen\&Seegers, 2009; Pavlou\&Damoka, 2006), online image (Schmallegger\& Carson, 2007; O’Connor, 2010), responses to online complaints, and the operational uses of online reviews (Torres, et al., 2013). Despite the amount resources devoted to monitoring online feedback in the lodging industry and the amount of time and efforts scholars have devoted to conducting research, little is known about the impact of such feedback on incremental revenue generation. Among the emerging literature in this subject is a study by Ye, Law, and Gu (2009) in which a mathematical model was developed to explain the impact of user-generated comments on hotel sales and profitability. Other researchers have explored the relationship of positive reviews and traffic to the business' website (Zhang, Ye, Law, \& Li, 2011). Despite the existing studies, more research is needed to demonstrate the effects of word-of-mouth communications in hotel bookings.

Concern for word-of-mouth communications (WOM) is not a new phenomenon. However, the existence of various channels to express consumer feedback has stirred a new wave of attention on the topic. Westbrook (1987) defined word-of-mouth as: "informal communications directed at other consumers about the ownership, usage, or characteristics of particular goods and services and/ or their sellers" (pp. 261). Researchers have posited that WOM has the potential to impact consumer purchase decisions, customer acquisition, and consequently result in increased revenue for organizations (Litvin, Goldsmith, \& Pan, 2008; Trusov, Bucklin, \&Pauwels, 2009). 
It can be argued that one of the goals of management research is to provide tools for current and future business leaders to make intelligent evidence-based decisions. Additionally given the investment that companies put forth towards maintaining a positive online image, it would be prudent to examine the likely returns from such efforts. Although research has started to examine financial performance measures as a consequence of consumer-generated feedback, many of these studies use proxy data to estimate actual financial measures. While this can be helpful in drawing attention to the research problem, the present study adds value by utilizing actual revenues from booking transactions. Additionally, while other studies have tried to link ratings to REVPAR (Blal \& Sturman, 2014), the present research examines the impact of rating, ranking and number of reviews on a hotel's ability to generate revenues through its booking transactions. In light of this, it can be stated that the purpose of this study is to explore the impact that a hotel's firm rating, relative ranking, and the overall number of reviews have on the average value of each booking transaction. Arguably, the present study can contribute to both the theory and practice of hospitality by exploring the links between various trends and practices and the hotel's financial measures. The following research objectives were proposed:

- To assess the impact of consumer-generated feedback on booking transactions

- Evaluate the role of a hotel's relative ranking on booking transaction

- Exploring the impact of the number of reviews on booking transactions

\section{Literature Review}

2.1 The financial outcomes of online feedback

While small in size, a nascent stream of literature exists to explore the role of online feedback on financial performance. As an example; Ye, Law, and Gu (2009) developed a 
mathematical model to explain the impact of user generated comments on hotel sales and profitability. Accordingly, a $10 \%$ improvement in reviews led to a $4.4 \%$ increase in sales. In a similar vein, Brian Ferguson (Executive Vice-President of Expedia) disclosed that according to his records "A one- point increase in a review score equates to a 9\% increase in ADR" (Lynch, 2012). The preliminary evidence proposed by both this mathematical model, as well as the data collected by industry professionals in online travel agencies, suggests that an impact exists between positive reviews and revenues. At the present time TripAdvisor is a very prominent online review site for hotels. Using consumer feedback, TripAdvisor (2013) applies a proprietary formula to assign hotels a ranking. Accordingly, this formula takes into account the number of reviews, age of the reviews, and quality (valence) of the reviews. Nevertheless, given the proprietary nature of such formula, the amount of emphasis placed on each factor, as well as any other factors not explicitly disclosed to the public is unknown.

Blal and Sturman (2014) studied the impact of ratings and volume of reviews on REVPAR. They demonstrated that there was a significant impact of ratings on the revenues per available room. However, the number of reviews didn't account for a significant shift. Blal and Sturman (2014) used a sample in London and thus the present study expands upon the existing knowledge by using a cross section of hotels in the United States. The present study examines a lodging establishment's financial data as measured by the average transaction size (in dollars). As such it provides a unique contribution, as higher transactions could potentially signify a customer's willingness to pay a premium for a room. Additionally information from Trip Advisor which was publicly available online, was used to explore the impact of ratings and number of reviews on the average size of an online transaction. 
Hoteliers want to see increased traffic to their proprietary websites. However, generating such traffic in the midst of a competitive landscape can present a challenge. Zhang, Ye, Law, and $\mathrm{Li}$ (2011) empirically tested such relationship and confirmed that there is a positive relationship between good reviews at a third party site and traffic to a business' proprietary website, in this case, a restaurant. Gu, Park, and Konana (2012) studied the relationship of internal and external Word-of-Mouth (WOM) on the sales of digital cameras. Their research demonstrated that sources of external WOM (in this case the third party review sites Epinions, DpReview, and Cnet) had a stronger influence on product sales as compared to the internally hosted sites such as Amazon. The study by Gu et al. (2012) is relevant in that the researchers studied a high-involvement purchase decision. Similarly, a hotel stay for many travelers is a high-involvement purchase decision due to the potentially high transaction costs, perceived risks, and other factors. Nevertheless, it is noteworthy that digital cameras remain a tangible product, and thus the consumer can potentially visit a local retailer, see, touch, feel, and try the product. The case of a hotel presents a product that is intangible; therefore the consumer doesn't have the ability to see the product live (though he / she might view pictures), touch, feel, smell, or try the hotel before visiting. Consequently, it's likely that the influence of WOM communications will be stronger for a hotel stay. Consistent with this notion, Senecal and Nantel (2004) posited that WOM would be more influential to purchasers of experiential products.

Whereas Ye et al.’s (2009) model suggests that improvement in reviews leads to greater sales; the study is based on proxy data. Consequently, confirming or disconfirming such results using revenue data from booking transactions can enhance scholar's understanding of consumergenerated feedback and manager's ability to implement successful strategies. Furthermore Zang et al's study (2011) posits that good reviews can lead to greater web traffic for restaurants. If the 
same principle was applied to hotel's website; greater traffic can be seen as a positive indicator. However, does such traffic lead to booking transactions? In light of our understanding on the role of positive online reviews on transactions and seeking to further examine this phenomenon, the researchers proposed the following hypothesis:

H 1: There is a significant relationship between a hotel's overall rating (i.e. 1, 2, 3 stars) on Trip Advisor and the hotel's average revenues from online transactions

It has been proposed that online sources can be used as a marketing tool. For example, some lodging properties have created photo contests for guests, and encouraged them to share videos and stories. Furthermore, hotels have used social networking to help guests interact with one another before a stay and create contacts to socialize during their visit (Kasavana, Nusair, \& Teodosic, 2010). Additionally, Schmalegger and Carson (2007) proposed enticing guests by granting vouchers. These can all be great examples of generating excitement through social media; however it's not clear whether hoteliers would get a return on the investment they make in such activities. Ye, et al. (2011) conducted an additional study in which they sought to explore the impact of positive online reviews on hotel sales. Nevertheless, due to the lack of financial data, the number of reviews was used as a proxy for hotel sales. Their study demonstrated that a higher valence of the average review rating leads to an increased number of reviews. Furthermore, they discovered that the variability in such comments was not as critical as the overall rating given by consumers in terms of generating a greater number of reviews (Ye, et al., 2011).

Hotels receive quality feedback from various stakeholders including consumers, experts, and internal sources. Torres et al. (2013) explored the operational implications of such feedback. 
Furthermore, the researchers discovered that the ratings of consumers and experts had been positively correlated with the perceptions of quality improvement of hotel General Managers. Ogut and Tas (2012) examined the impact of both expert ratings (in this case online ratings), and consumer ratings (through comments posted in an online travel agency). Such study sought to understand the impact of experts and consumer's opinions on hotel sales in two major tourist destinations: Paris and London. In a similar manner than Ye et al. (2011), researchers Ogut and Tas (2012) utilized the number of reviews as proxy for sales. Their findings suggest that consumer ratings impact the number of reviews more so than the ratings of experts. Of greater importance is the fact that the authors demonstrated a positive relationship between consumer ratings and the lodging establishment's average price of a standard double room during the data collection period (Ogut and Tas, 2012).

A business' online reputation can be positively or negatively affected by online feedback. Seeking to explore the impact of electronic WOM in the ability to generate price premiums, Ba and Pavolu (2002) conducted both an experimental and a field study based on e-bay's feedback forum. In their experimental study, researchers were able to demonstrate that both positive and negative ratings impact a seller's credibility. Nevertheless, negative comments were found of greater impact in credibility. Similarly, Ba and Pavolu's (2002) study revealed that with higher levels of trust in a seller, consumers were willing to pay more for the same product. When testing their experimental findings in a field setting, the authors confirmed that the level of trust in the seller does indeed impact price premiums. Nevertheless, unlike the experimental study, the field study didn't provide evidence to justify the premise that negative feedback has a greater effect on trust than positive WOM. Ba and Pavolu's (2002) examination of price premiums aids in scholar's understanding of the effects of consumer-generated feedback, nevertheless the usage of 
one auction-based forum based on physical products leaves a question as to the applicability of these principles in a service setting. Given the experiential nature of a hotel stay, it would be pertinent to further study the impact of online feedback on the hotel's ability to set a price premium and ultimately generate higher revenues.

\subsection{Consumer decision-making based on online feedback}

Much of the scholarly attention on the subject of consumer-generated feedback has centered on the idea of consumer-decision making. In the process of making decisions, consumers consult others who might provide useful insights as to their experience with a product or service. Such communications are typically referred as WOM, and though not new, their incidence has dramatically increased with the advent of electronic forms (EWOM). Torres et al. (2013) organized the various sites into three categories: online feedback site (i.e. TripAdvisor, Yelp), social networking site (i.e. facebook, twitter), and online travel agencies (i.e. expedia, Travelocity).

In the course of exploring consumer decision-making, scholars have paid particular attention to the preservation of a hotel's online image. Research by Cox, Burgess, Sellitto, and Buutjens (2009) suggested, that consumers are more likely to utilize consumer - generated content at the information gathering stage of the purchase decision process. It has also been suggested that people rarely view comments beyond the first two pages in feedback sites (Pavlou and Domoka, 2006). Sparks \& Browning (2011) studied whether or not the existence of a numerical rating impacted consumer decisions. They discovered that numerical ratings were only relevant when accompanied by verbal feedback. Online reviews can increase the visibility of a lodging property. In particular, sites like Trip Advisor rank hotels within their competitive 
market. However the financial impact of a certain raking has not been measured. Consequently, the following hypothesis was proposed:

H 2: There is a significant relationship between a hotel's overall ranking $\left(1^{\text {st }}, 2^{\text {nd }}, 3^{\text {rd }}\right)$ on Trip Advisor and the hotel's average revenues from online transactions

Consumer-generated feedback is not limited to the lodging industry. Many products and services are evaluated on a daily basis. For example, Chevlier and Mayzlin (2006) explored the impact of online feedback on electronic book sales. Duan, Gu, and Whinston (2008) studied the impact of reviews on box office sales. Gu et al. (2012) examined the impact of electronic WOM on sales of digital cameras and Ba and Pavolou (2002) studied the impact of electronic feedback on a seller's ability to place price premiums through e-bay. Yet many others have explored the impact of consumer-generated feedback in the hotel industry (O'Connor, 2010; Ogut and Tas; 2012 Torres, et al., 2013; Ye, et al., 2011) . Despite the importance to various products and services, it has been suggested that importance of such reviews is not the same across industries. In fact, research has revealed that consumer-generated feedback is more important to prospective purchasers of experiential products (Senecal \& Nantel ,2004). In their study of consumer decision making and social media, Vermeulen and Seegers (2009) reveled that reviews can help consumers move from a universal set of choices to a consideration set. In other words, reviews are used by consumers to narrow down the choice of product or service. The researchers also explored weather independent or chain hotels will be similarly impacted. It was revealed that the use of consumer-generated feedback had a greater effect on independent lodging establishments (Vermeulen \& Seegers, 2009). 
Given the increased reliance on online feedback to make purchase decisions, it is prudent to determine the accuracy and integrity of such comments. It has been suggested that some challenges commonly associated with online feedback include: bias, statements that are very broadly written, and the potential for information overload (O’Mahony \& Smyth, 2009). Debate exists as to the relative importance consumers assign to such content, as compared to other sources. Cox et.al. (2009) proposed that consumer-generated feedback might not be viewed as trustworthy as other sources. Goh, Heng, and Lin (2013) compared content generated by users versus that of competitors. The authors concluded that both content is important, though usergenerated content has a stronger impact on purchase behaviors. The lack of control and verification processes for the information posted makes it vulnerable to people who post false information about a particular hotel. Torres et al. (2013) compared the reviews of consumers and experts. It was discovered that despite both groups using different criteria; their scores were positively correlated.

Schmalegger and Carson (2007) discussed both the opportunities and challenges associated with alternatives such as hiring an experienced and professional blogger and letting employees blog about their companies. Noone, McGuire, and Rohlfs (2011) suggested that revenue managers have various opportunities to engage with customers through various social media channels. Essentially online feedback can inform their promotional and pricing decisions such as the configuration of promotions and packages, as well as the execution of push strategies. Furthermore, revenue managers can inform their strategies regarding pricing, distribution channels, and also have the potential to develop micro-sites targeted at specific customer groups (Noone, et al., 2011). In spite of the growing concerns about the reliability of such data, research by O'Connor (2010) suggests that very few of the comments presented today 
at such sites can be considered suspect. However, there is not agreement among scholars concerning the specific incidence of deceitful reviews.

2.3 The operational implications of user-generated content

Whereas many have explored the use of consumer-generated feedback for marketing purposes; this is certainly not its only use. Online feedback can serve as the basis for a series of management actions including responding to feedback, targeting investments in amenities that consumers would desire, and perpetuating positive actions that lead to customer delight. Therefore, blogs and other consumer generated feedback can furnish valuable information to hotel managers that will help drive their quality results (Schmallegger\& Carson, 2007). Accordingly, this information can help them track the attitudes, opinions, and satisfaction of guests over the course of time.

Torres, et al. (in press) studied the use of consumer-generated feedback for operational and quality purposes. It was discovered that $90 \%$ of all General Managers reviewed such feedback on a daily basis. Trip Advisor was the most monitored and most valued source of online feedback according to this study. General Managers were asked to rate the various activities emerging from the use of consumer-generated feedback. One of the most important activities was identifying patterns of complaints, whereas using such information to make changes in operating procedures was not as practiced by GM's. The researchers also discovered that those General Managers who placed greater value on consumer-generated feedback were more likely to improve the perceived hotel quality (Torres et al., in press).

One of the practices that lodging properties utilize is to respond to online consumer feedback. Park and Allen (2013) explored the impact of management responses to customers 
online. Their research identified three groups of companies: frequent responders, infrequent responders, and non-responders. Hotels that responded frequently believed that online feedback was mostly a fair representation of consumer's feelings. In contrast, those who did not respond frequently were more likely to perceive the reviews as extreme or biased. The authors suggested that hotels need to go beyond simply reacting to consumer feedback, and develop strategies to foster positive online relationships (Park and Allen, 2013). Whereas many managers have focused their efforts in minimizing the damage of negative reviews, encouraging positive reviews can be a more beneficial strategy. A recent study by Melian-Gomez, Bulchand-Gidumal, and Gonzalez-Lopez, (2013) proposes that as the number of online reviews increases, a better evaluation is obtained. Although this can point to the need to increase the number of reviews, the specific monetary impact of reviews is unknown. Consequently, the following hypothesis was proposed:

H 3: There is a significant relationship between a hotel's overall number of online reviews on online feedback sites and the hotel's average revenues from online transactions

Another area of interest pertains to the actions taken by the management of a hotel following positive or negative online feedback. According to Yu (2010), less than $4 \%$ of the negative online reviews receive a response by a hotel manager. Given the vast amount of online feedback, hoteliers are turning to companies who offer specialized software such as Revinate to manage the vast amount of online content. Hanson in Yu (2010) stated that some managers use reviews to improve training, adjust staffing levels, and add or remove amenities. The literature on the use of consumer-generated feedback proposes that such information can be used to improve the quality of a hotel's operations. 


\section{Research Methods}

In order to obtain and analyze the data needed for this study, researchers from both the University of Central Florida and consulting company Travel Click joined forces. Travel Click was able to gather a sample of 178 hotels from the United States. These lodging establishments represent a cross-section of corporate, managed, and independent hotels. They were also located in different cities and catered towards different guests (i.e. business, leisure, convention). Relevant information from these hotels included the number of online booking transactions, the total revenue derived from online bookings, and the average value of each booking transaction for several hotel companies. The average value was obtained by taking the total booking revenue for a hotel and dividing it by the number of booking transactions. Data was collected from two months of revenue (July and August of 2013).

Researchers from the University of Central Florida took the database of these lodging properties after the financial information was collected and examined their Trip Advisor page. Relevant data included the hotel's rating, ranking and number of reviews. A hotel rating is the rating that is given by Trip Advisor to each lodging establishment (i.e. 1, 2, 3, 4, 5 stars) based on the totality of the consumer comments received. The ranking relates to the placement of each hotel within its competitive set (i.e. a hotel is $1^{\text {st }}, 2^{\text {nd }}$, or $3^{\text {rd }}$ in a given city). The number of reviews includes the total number of reviews for a specific hotel regardless of the valence of such comments. In order to control for the effects of hotel size, formal rating, and location, the researchers collected additional data. First, the hotel size was calculated by using the number of rooms in each one of the hotels under study. Second, a formal rating of the hotel was obtained by examining the American Automobile Association (AAA) list of diamond lodgings and Forbes Star ratings for hotels in the United States. When a hotel was rated by neither AAA nor Forbes, 
the first named author assigned an expert start rating based: a) amenity descriptions from the hotel's proprietary site (i.e. availability of room service, bell service, valet, concierge, turndown service, recreation facilities, restaurants, etc.); b) pictures from the hotel's proprietary site (e.g. special emphasis given to materials used in countertops, flooring, furnishings, light fixtures, bedding package, age of the product, etc); c) rating (non-consumer) given by Expedia, and; d) rating (non-consumer) given by Booking.com. The first named author has previous experience working as a quality assurance consultant for an independent firm and has helped numerous hotels prepare for their AAA and Forbes evaluations. Third, the researchers controlled for the effects of location by examining the gross median rent for each of the cities in which the hotels were located. Cities with higher real estate costs typically command higher rents and higher hotel daily rates. Average rent information was obtained through “American Fact Finder” (2015), a service of the US Census Bureau. By using the gross median rent in a city, the researchers ensured that the data was not being strongly influenced by the specific city in which a hotel was located.

Multiple regression analysis was performed. The outcome variable for the study was the average transaction value and the independent variables were: a) hotel rating, b) hotel ranking, and c) number of reviews. Analysis was conducted utilizing SPSS 21.0. Additionally, the appropriate testing for the regression assumptions was performed. No regression assumptions were violated during the analysis. Additionally, multiple regression analysis was done for each of the months separately. There was no significant difference in the results of July versus August of 2013, thus the relationships (or lack thereof) in the results remained constant. 


\section{Results}

In order to determine the relationship among the variables of interest, multiple regression analysis was performed between the hotel's average revenues generated from online transactions as the dependent variable with the three independent variables (a lodging property's overall rating, hotel's overall ranking, and overall number of online reviews posted for a hotel). The results of the regression analysis are presented in Table 1 . The " $R$ " for the regression was significantly different from zero, $F(3,134)=15.20, p<.001$, with $R^{2}$ at 0.25 . The adjusted R-

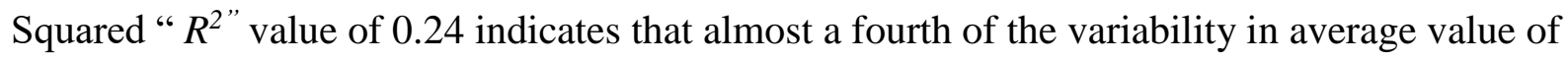
hotel's online transactions is predicted by the number of reviews, hotel rating, and hotel ranking on the websites.

The multiple regression model under testing, demonstrated a p-value of 0.000 for the coefficient of differentiation, therefore such model can be considered to have acceptable levels of statistical significance. The plot of residuals indicates that the data follow linearity and normality conditions without any homoscedasticity. The tolerance values of the independent variables gave no indication of multicollinearity, with the highest tolerance value being less than 1.37. Of the regression coefficients, except for the hotel's overall ranking, all the other variables have a significance level of less than 0.001. Such results further confirm the significant impact of the independent variables on the dependent variable. Since the variables were mostly scaled differently, their relative significance can be compared only on the basis of the standardized beta coefficient. As part of the multiple regression model, the researchers were able to quantify the effects of rating and number of reviews on online revenue generation. Each TripAdvisor star equated to an incremental $\$ 280$ per booking transaction. Similarly, each review represented a total of $\$ 0.12$ per booking transaction. Please see the tables below for more details. 


\section{>>> Insert Table 1 around here $<<<<~$ >>> Insert Table 2 around here $<<<<~$}

In order to examine the relationship among TripAdvisor reviews and hotel revenues and considering the potential for additional variables to influence results, the researchers tested a second multiple regression model. In this second model, the average value of online transactions remained as the dependent variable. In addition to Trip Advisor rating, ranking, and number of online transactions, the researchers added the following control variables: a) size of the hotel (as measured by the number of rooms), b) star or diamond rating of the hotel, c) location effects (controlled by using the gross median rent for each city). Overall, the model was a good predictor of average transaction value, as demonstrated by the r-square statistic of 0.383 , thus $38 . \%$ of the variance in the average transaction value can be explained by the independent variables. The multiple regression model was statistically significant $(\mathrm{F}=12.67, \mathrm{P}$-Value $=$ .000). When examining the specific independent variables in the model, Trip advisor rating proved to be statistically significant ( $\mathrm{p}$-value $=.001$ ), and so did the number of reviews ( $\mathrm{p}$-value $=.00)$. The ranking of a hotel was not statistically significant at the .05 level. Please, see table 3 for details. After testing for the assumptions of multiple regression, the researchers ascertained that no assumptions were violated.

\section{>> Insert Table 3 Here $<<<$}

The first stated hypothesis proposed that a significant relationship exists between a hotel's rating on Trip Advisor and the average revenues generated per online transaction. Regression analysis revealed that $\mathrm{H} 1$ is significant at the .05 level. Consequently, the findings support the positive relationship between a consumer rating (i.e. 1, 2, 3 stars) and higher online 
transaction average value. The second hypotheses proposed that a hotel's raking (as revealed by the position in its competitive marketplace $-1^{\text {st }}, 2^{\text {nd }}, 3^{\text {rd }}$ ) on feedback sites is positively related to the average value per online transaction. Such hypothesis was not supported by the data. The third and final hypothesis proposed that the number of online reviews of a particular lodging establishment will have a positive impact in the size of the average online transaction.

Regression analysis revealed that there is a positive correlation between the number of reviews and the average revenues derived from each online transaction. Therefore, hypothesis was supported. Based on the results of the research, a model was established (see Figure 1)

\section{>>>Insert Figure 1 here $<<<$}

In addition to the stated hypotheses, the authors performed analysis of other relevant variables. Since TripAdvisor is not the only place where customers can voice their opinion, the researchers examined consumer-generated feedback via online travel agency (OTA) Expedia. Whereas most OTA's allow customers to rate hotels and other services, Expedia is the largest of these agencies and thus was selected for analysis. The ratings were obtained for each of the hotels analyzed. The Mean Expedia comment was 4.2, whereas the average TripAdvisor score was 4.0. A correlation of .714 was noted between TripAdvisor ratings and Expedia Ratings. A paired sample t-test was conducted to ascertain whether the means were significantly different. The results demonstrate that there are statistically significant differences among ratings furnished by TripAdvisor and those disclosed by Expedia $(\mathrm{t}=6.62, \mathrm{p}$-value $=.00)$. Furthermore, regression analysis demonstrated that Expedia ratings are significantly related to average transaction values $(\mathrm{F}=17.66, \mathrm{p}$-value $=.00)$. Nevertheless, when paired against TripAdvisor ratings on a multiple regression model, TripAdvisor rating was a better predictor of average transaction value, as compared to Expedia ratings. 


\section{Discussion}

The present research sought to gain a better understanding of the impact that online consumer feedback has on hotel financial outcomes. More specifically, it was demonstrated that a lodging property with a higher overall rating and a large number of reviews can reap the rewards of such customer feedback. The researchers examined the impact on a specific financial outcome: average value of booking transaction. A higher value per transaction generates more revenue per customer, which all things being equal could result in better profitability. Higher value per transaction may also indicate a premium that customers are willing to pay based on the quality of the services the hotel provides. Therefore, hotels that are highly ranked might be viewed by customers as having a different value proposition than those that are not.

The number of reviews was also particularly relevant to the present study. A greater number of reviews can indicate more popularity for a hotel. Since the number of reviews positively impacted the average value per transaction, hoteliers can create strategies aimed at generating a large pool of customers who write reviews. The present study did not distinguish positive from negative reviews; it only examined the total number of reviews. The central argument behind this choice was that simply increasing the number of reviews could be beneficial. Trip Advisor (2014) in its proprietary algorithm admits to using the number of reviews as part of its popularity index. Consequently, the authors argue that simply increasing the number of reviews can be beneficial regardless of their valence in that it might help improve TripAdvisor ranking and rating. Furthermore, it's possible that with greater number of reviews, the impact of extreme reviews is minimized and a central tendency might be obtained. As to the likely impact of greater number of reviews with a positive valence, the authors would argue that 
the impact could potentially be further expanded. Increasing the number of reviews can be beneficial for a lodging establishment in various ways including increasing transaction value. In support of the idea of generating more reviews, Melian-Gomez, Bulchand-Gidumal, and Gonzalez-Lopez (2013) discovered that as the number of online reviews increases, the customer evaluation rating is improved. While many hotel managers may fear the negative feedback, a pro-active approach to generating feedback can ensure not only that the hotel gets much needed volume of comments on Trip Advisor, but also that such comments are from delighted guests who will rank the hotel higher as opposed to their satisfied, dissatisfied, or outraged counterparts. Torres et al. (2013) studied the operational implications of consumer-generated feedback and stressed the role of hoteliers in developing strategies to manage their online image. Similarly, Schmallegger and Carson (2007) also proposed various pro-active strategies to ensure a positive online image.

One of the hypotheses of this study was not supported. The hotel's ranking did not have a significant impact in the overall transaction. A hotel's ranking is its relative position in Trip Advisor when compared to competitors (i.e. $1^{\text {st }}, 2^{\text {nd }}, 3^{\text {rd }}$ ) in their local area. A possible explanation is that within a given city, hotels of various quality ratings (i.e. 3, 4, 5 stars) are paired together by Trip Advisor in the same competitive set. Since a lower star hotel generates typically commands a more inexpensive hotel rate, it's possible this could have an impact in the overall regression of ranking against average transaction value. In light of this, it can be stated that the most important thing for a lodging establishment is not always to be first or second in their city, but rather to be first or second within their quality comparable competitive set. In other words, a hotel that has a four star rating, might be more concerned with other four star hotels in their area that might have a higher position in Trip Advisor. More importantly, such hotels 
should concern themselves more with their overall individual rating, as opposed to the market ranking based on research results. Moreover, the researchers did not obtain the specific information concerning how Trip Advisor ranks of these properties, such as which variables were included and how they were weighted. Such information is kept proprietary by Trip Advisor. Hence, future studies must look into the composition of these rankings to get a better insight so as to why average booking revenue does not have any impact of the hotel ranking.

\section{Practical Implications}

Through the research result, the authors underscore the need to monitor online feedback. Hoteliers will do well in encouraging their very satisfied or delighted customers to post online reviews. For example, if a customer rates the hotel highly on its customer satisfaction survey or writes a letter or E-Mail to the hotel's management, such customer should be directed to post a comment on feedback sites such as Trip Advisor, Yelp or others. Furthermore, providing the opportunities for customers to do so while on property can increase the likelihood of customers writing such reviews. Hoteliers can also take into account customer feedback to direct resources towards capital investments that will help drive comments upwards. For example, a great incidence of negative comments regarding a lodging's fitness center, can point attention to the need for renovations or upgrades of such facility.

Many times industry professionals are eager to increase occupancy numbers for a hotel. However, an emphasis on quality bookings can yield good results for a hotel. When good customer feedback exists online, a hotel can increase the average size of each online transaction, thus have each customer pay more than they would in an otherwise lower-ranked hotel. A hotel 
who suffers in the online feedback world, is also likely to generate less revenue per transaction and this could lead to lower profitability. Hotel owners and management companies will do well in keeping management accountable for the hotel's online reputation and keep track of how it affects the return on their investment.

The number of online transactions is very important for lodging establishments. More numbers lead to more revenues according to the present study's results. Therefore, generating a good volume of reviews is critical for a hotel's financial health. More number of reviews and better quality of reviews can indicate both quality and popularity of a hotel and thus command a better rate in the marketplace, as compared to similar establishments.

\section{Limitations and Future Research}

Although the present study sought to explore the revenues generated by hotel's based on online feedback using actual financial data, it does have some limitations. Revenue performance was measured with one outcome variable: the average value per online transactions. Future research can examine other hotel financial measures such as RevPar, Occupancy. The study uses a sample of 178 hotels within the United States. Future research can examine specific markets within the United States or in other countries. The quantitative nature of the present research, allowed establishing relationships among the variables. However, future research could benchmark the top performers on Trip Advisor from a qualitative perspective and ascertain common practices among them using a qualitative approach. Whereas the present quantitative approach reveals the relationships among variables, qualitative approaches could reveal the reasons behind the relationships. Interviews could be conducted with customers and hotel managers to ascertain their perceptions of the TripAdvisor's popularity index in their willingness 
to pay. Furthermore, case analysis of various lodging properties could examine how an increase or decrease in ratings and rankings affected their revenues over the course of time. The present research used a sample of hotels of different brand affiliations, independent lodgings, small and large hotels. Future research could examine the number of rooms per hotel, and brand affiliation and determine its likely impact on the hotel rating, ranking, and number of reviews on feedback sites such as Trip Advisor.

Not being able to include many other factors such as overall demand, location, and service levels, among others; that can influence revenue but are not score dependent was the major limitation of this study. However, future research can attempt to collect all these other variables. The main focus of the present study was limited to only online reviews for this data since the researchers did not have access to other influential variables data. The researchers have attempted to answer the research questions with data availability limitation. Consequently, this was a limitation that future studies might try to address. Additionally, there could be any number of potential variables which may influence sales revenues such as advertising, and brand image among others: future research may collect all these other variables.

Many of today's managers are concerned about their online image. Scholars have been equally concerned about the emergence of consumer-generated feedback and have studied related topics. In today's dynamic business world, it's not enough to simply show concern or monitor such feedback, hoteliers need to have a strategy to process such information and reap the rewards of higher ratings and number of reviews. Scholars can continue to expand this emerging field of knowledge by proposing theoretically sound and practically applicable research. 


\section{Conclusion}

In the introduction section, the researchers proposed three objectives. In this section, the authors recapitulate such statements and provide answers based on research:

- To assess the impact of consumer-generated feedback on booking transactions

- The quality of consumer generated feedback has an impact on booking transactions. More specifically, a higher star rating will lead to online transactions of higher dollar value.

- Examine the role of a hotel's relative ranking on booking transaction

- A hotel's relative raking does not seem to have the same effect on the average booking transaction. The study results don't support such relationship. Having said this, it's likely that the position of a lodging establishment online determines whether a customer will read or ignore the rating, especially in markets with large number of hotels.

- Exploring the impact of the number of reviews on booking transactions

- The number of reviews has a positive impact on the average value per online transaction. The more reviews a hotel receives, the better quality of booking it will obtain.

The present research demonstrates the impact of consumer-generated feedback on a hotel's financial performance. Often times, a hotel designs its revenue strategy solely based on supply and demand factors. However, the present research proposes that consumer factors, especially the online world-of-mouth can impact a hotel's ability to exert pricing power, all things being equal. It is therefore incumbent on scholars and practitioners to examine the factors 
that can lead to a higher online transaction. As hotels seek to please their guests from at a practical level and as scholars seek to understand guests from a psychological perspective; everyone will have better tools to make intelligent, evidence-based decisions that will both please the guests, and result in better financial outcomes.

\section{References}

American Fact Finder (2015). Retrieved electronically on July 1, 2015 from http://factfinder.census.gov/faces/nav/jsf/pages/index.xhtml

Ba, S., \& Pavlou, P. (2002). Evidence of trust building technology in electronic markets: Price premiums and buyer behavior. MIS Quarterly, 26 (3), 243-268.

Blal, I., \& Sturman, M. (2014). The differential effects of the quality and quantity of online reviews on hotel room sales. Cornell Hospitality Quarterly, 55 (4), 365-375.

Chevlier, J., \& Mayzlin, D. (2006). The effect of word-of-mouth on sales: Online book reviews. Journal of Marketing Research, 43 (3), 345-354.

Cox, C., Burgess, S., Sellito, C., \& Buultjens, J. (2009).The role of user-generated content in tourists' travel planning behavior. Journal of Hospitality Marketing \& Management, 18, 746-764.

Duan, W., Gu, B., \& Whinston, A. (2008). Does online reviews matter? - An empirical investigation of panel data. Decision Support Systems, 45 (4), 1007-1016.

Goh, K., Heng, C., \& Lin, Z. (2013). Social media brand community and consumer behavior: Quantifying the relative impact of user- and marketer-generated content. Information Systems Research, 24 (1), 88-107. 
Gu, B., Park, J., \& Konana, P. (2012). The impact of external word-of-mouth sources on retailer sales of high-involvement products. Information systems research, 23 (1), 182-196.

Kasavana, M., Nusair, K., \&Teodosic, K. (2010). Online social networking: Redefining the human web. Journal of Hospitality and Tourism Technology, 1(1), 68-82.

Litvin, S., Goldsmith, R., \& Pan, B. (2008).Electronic word-of-mouth in hospitality and tourism management. Tourism Management, 29 (3), 458-468.

Lynch, J. (2012, January 10). Online review reputation management trends for hotels in 2012. Sabre Hospitality Solutions. Retrieved on February 6, 2012 from http://www.sabrehospitality.com/blog

Melian-Gomez, S., Bulchand-Gidumal, J., \& Gonzalez-Lopez, B. (2013). Online customer reviews: As participation increases, better evaluation is obtained. Cornell Hospitality Quarterly, 54 (4).

Noone, B., McGuire, K., \& Rohlfs, K. (2011). Social Media meets hotel revenue management: Opportunities, issues, and unanswered questions. Journal of Revenue and Pricing Management.10 (4), 293-305.

O’Connor, P. (2010). Managing a hotel's image on TripAdvisor. Journal of Hospitality Marketing \& Management, 19, 754-772.

Ogut, H., \& Tas, B. (2012). The influence of internet customer reviews on online sales and prices in the hotel industry. The Service Industries Journal, 32 (2), 197-214.

O’Mahony, M., \& Smyth, B.(2010). A classification-based reviewer recommender. KnowledgeBased Systems, 23 (4), 323-329.

Park, S., \& Allen, J. (2013). Responding to online reviews: Problem solving and engagement in hotels. Cornell Hospitality Quarterly, 54 (1), 64-73. 
Pavlou, P. A., \& Dimoka, A. (2006). The nature and role of feedback text comments in online marketplaces: Implications for trust building, price premiums, and seller differentiation. Information Systems Research, 17(4), 392-414.

Schmallegger, D., \& Carson, D. (2007). Blogs in tourism: Changing approaches to information exchange. Journal of Vacation Marketing, 14(2), 99-110.

Senecal, S., \&Nantel, J. (2004).The influence of online product recommendations on consumers' online choices. Journal of Retailing,80, 159-169.

Sparks, B. A., \& Browning, V. (2011).The impact of online reviews on hotel booking intentions and perception of trust. Tourism Management, 32 (6), 1310-1326.

Torres, E. N., Adler, H., Lehto, X., Behnke, C., \& Miao, L. (2013). One experience and multiple reviews: The case of upscale US hotels. Tourism Review, 68(3), 3-20.

Torres, E.N., Adler, H., Behnke, C., Miao, L., Lehto, X. (in press). The use of consumer generated feedback in the hotel industry: Current practices and their effects on quality. International Journal of Hospitality and Tourism Administration, 16 (3).

TripAdvisor (2013, July 26). FAQ-TripAdvisor popularity ranking: Key factors and how to improve. Retrieved electronically on December 3, 2014 from http://www.tripadvisor.com/TripAdvisorInsights/n684/tripadvisor-popularity-rankingkey-factors-and-how-improve

Trusov, M., Bucklin, R., \& Pauwels, K. (2009). Effects of word-of-mouth versus traditional marketing: Findings from an internet social media site. Journal of Marketing, 73, 90-102.

Vermeulen, I. E., \& Seegers, D. (2009). Tried and tested: The impact of online hotel reviews on consumer consideration. Tourism Management,30, 123-127. 
Westbrook, R. (1987). Consumption-based affective responses and post-purchase processes. Journal of Marketing Research, 24 (3), 258-270.

Williams, R., Van der Wiele, T., Van Iwaarden, J. , \& Eldridge, S. (2010). The importance of user-generated content: The case of hotels. The TQM Journal, 22(2), 117-128.

Ye, Q., Law, R., \& Gu, B. (2009). The impact of online user reviews on hotel room sales. International Journal of Hospitality Management, 28, 180-182.

Ye, Q., Law, R., Gu, B., \& Chen, W. (2011). The influence of user-generated content on travel behavior: An empirical investigation on the effects of e-word-of-mouth to hotel online bookings. Computers in Human Behavior, 27, 634-639.

Yu, R. (2010, March 23). Hotel managers monitor online critiques to improve service. USA Today. Retrieved February 6, 2012 from http://www.usatoday.com

Zhang, Z., Ye, Q., Law, R., \& Li, Y. (2011). The impact of e-word-of-mouth on the online popularity of restaurants: A comparison of consumer reviews and editor reviews. International Journal of Hospitality Management, 29(4), 694-700. 